\title{
Accidental Dural Pith during Localization in Anterior Cervical Surgery: An Ounce of Prevention is Worth a Pound of Cure
}

Sir,

A 19-year-old male presented with neck pain following a road traffic accident and imaging revealed a Hangman fracture [Figure 1a and $\mathrm{b}$ ]. He was posted for reduction of the dislocation, C2-C3 anterior cervical discectomy, and interbody grafting and fixation. Following exposure up to the prevertebral fascia, the correct level for surgery was localized using intraoperative fluoroscopy after inserting a 20-G lumbar puncture needle into the exposed disc space through the anterior longitudinal ligament. Unfortunately, lateral views revealed that the needle had gone beyond the posterior cortex of the vertebra into the spinal canal [Figure 2a]. Anteroposterior views [Figure 2b] showed that the needle tip was lying laterally in the canal on the left side. The needle was carefully withdrawn, and surgery was continued. After discectomy was done and posterior longitudinal ligament (PLL) was cut, the puncture point in the dura was visible with occasional drops of cerebrospinal fluid (CSF) coming out of it. This egress later stopped spontaneously. Onlay surgicel was placed, interbody grafting and fixation was done, and postextubation the patient had no deficits.

The incidence of CSF leak following dural injury after any type of anterior cervical spinal surgery is estimated to be about $1 \%{ }^{[1]}$ The incidence is more in multilevel surgery, surgery for ossified PLL, and in reoperations. ${ }^{[1]}$ However "pithing" the thecal sac during localization, as occurred in our case, has not been mentioned as a cause of the same though a case of accidental self "pithing" by an acupuncture needle ${ }^{[2]}$ is reported in literature.

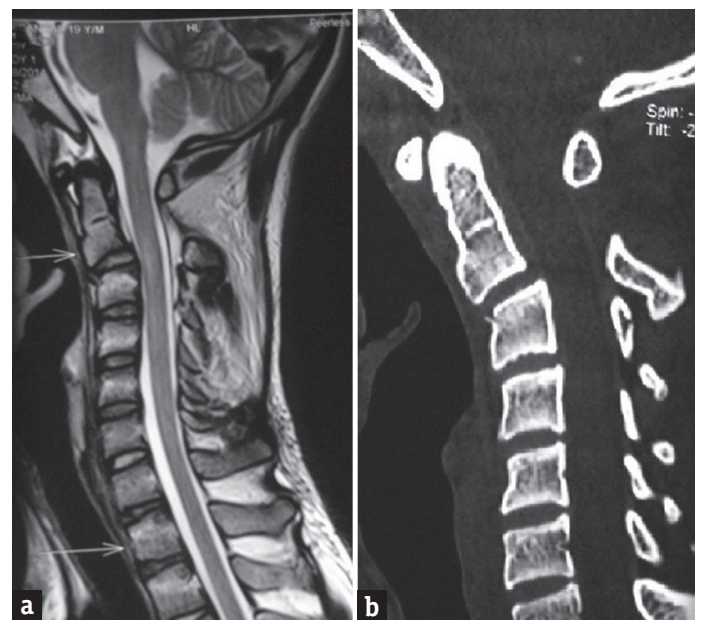

Figure 1: Preoperative sagittal magnetic resonance (a) and computed tomography (b) images showing anterolisthesis of $\mathrm{C} 2$ on $\mathrm{C} 3$ due to the Hangman fracture
To prevent such an intraoperative complication, Hanbali et $a l^{[3]}$ advocate bending the spinal needle at the tip to prevent it from advancing into the spinal canal. Furthermore, angling the needle upward will cause it to encounter the endplate of the vertebra above instead of going intradurally (which would happen if it was introduced parallel to the endplates of the vertebra). We have encountered this complication during localization in only one of 347 cases of cervical spine surgery done by the anterior approach done at our center. This was due to carelessness on the part of the operating surgeon in skipping the step of creating a bend in the localizing needle (which has since never been repeated). The right-sided approach and handedness of the surgeon resulted fortunately in a lateral trajectory of the needle that missed the cord and only caused dural injury.

Persistent CSF leak following dural injury runs the risk of pseudomeningocele formation and meningitis. If such leak is detected, options vary from conservative treatment, epidural blood patch, intraoperative closure using fibrin glue with overlay fascial patches, and even postoperative introduction of insertion of a lumbar drain. As "an ounce of prevention is worth a pound of cure," due diligence in following each step of surgery can prevent such an iatrogenic complication.

\section{Financial support and sponsorship Nil.}

\section{Conflicts of interest}

There are no conflicts of interest.

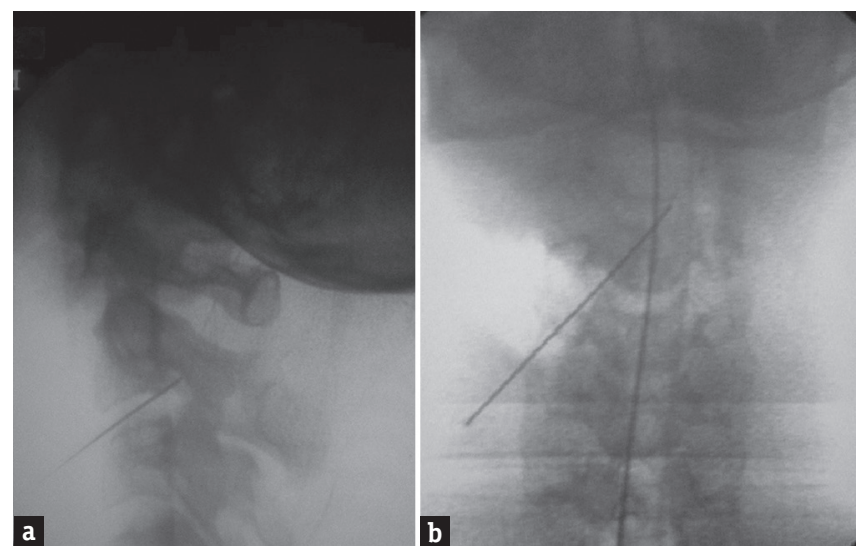

Figure 2: Intraoperative fluoroscopic images (a) lateral and (b) anteroposterior showing localizing needle inadvertently penetrating the spinal canal (more towards the left side) 
Dhruv Kumar Agarwal, Eswararao Thamatapu, Rajaraman Kartikueyan, Prasad Krishnan

Department of Neurosurgery, National Neurosciences Centre, Kolkata, West Bengal, India

Address for correspondence: Dr. Prasad Krishnan, Department of Neurosurgery, National Neurosciences Centre, Peerless Hospital Campus, $2^{\text {nd }}$ Floor, 360 Panchasayar, Kolkata - 700 094, West Bengal, India. E-mail: prasad.krishnan@rediffmail.com

\section{REFERENCES}

1. Zeidman SM. Cervical cerebrospinal fluid leakage, durotomy and pseudomeningocele. In: Benzel EC, Connolly PJ, editors. The Cervical Spine. $5^{\text {th }}$ ed. Philadelphia: Lippincott Williams and Wilkins; 2012. p. 1294.

2. Anderson DW, Datta M. The self-pith. AJNR Am J Neuroradiol 2007;28:714-5.

3. Hanbali F, Gokaslan ZL, Cooper PR. Ventral and ventrolateral subaxial decompression. In: Steinmetz MP, Benzel EC, editors. Benzel's Spine Surgery: Techniques, Complication Avoidance, and Management. $4^{\text {th }}$ ed. Philadelphia: Elsevier Inc.; 2016. p. 496.

This is an open access article distributed under the terms of the Creative Commons Attribution-NonCommercial-ShareAlike 3.0 License, which allows others to remix, tweak, and build upon the work non-commercially, as long as the author is credited and the new creations are licensed under the identical terms.

\begin{tabular}{|l|l|}
\hline \multicolumn{2}{|c|}{ Access this article online } \\
\hline Quick Response Code: & Website: \\
\hline & \\
\cline { 2 - 2 } & \\
\hline
\end{tabular}

How to cite this article: Agarwal DK, Thamatapu E, Kartikueyan R, Krishnan P. Accidental dural pith during localization in anterior cervical surgery: An ounce of prevention is worth a pound of cure. J Neurosci Rural Pract 2017;8:S152-3.

๑ 2017 Journal of Neurosciences in Rural Practice | Published by Wolters Kluwer - Medknow 